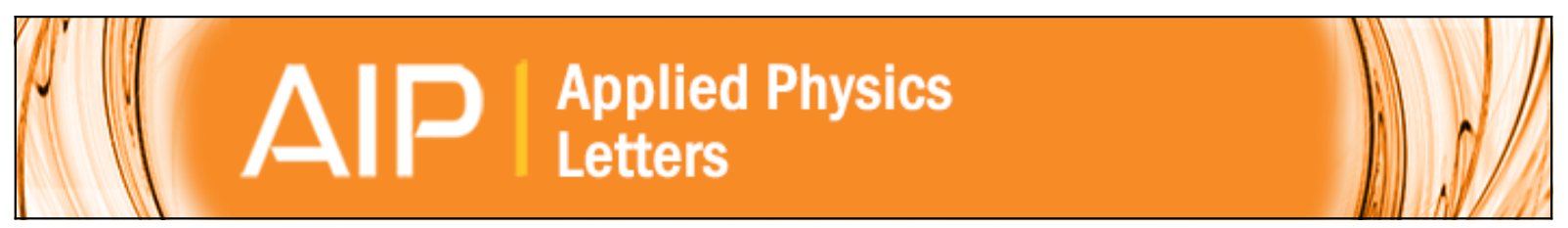

\title{
Strong enhancement in thermal conductivity of ethylene glycol-based nanofluids by amorphous and crystalline Al2O3 nanoparticles
}

J. Gangwar, A. K. Srivastava, S. K. Tripathi, M. Wan, and R. R. Yadav

Citation: Applied Physics Letters 105, 063108 (2014); doi: 10.1063/1.4893026

View online: http://dx.doi.org/10.1063/1.4893026

View Table of Contents: http://scitation.aip.org/content/aip/journal/apl/105/6?ver=pdfcov

Published by the AIP Publishing

\section{Articles you may be interested in}

Investigation of thermal conductivity, viscosity, and electrical conductivity of graphene based nanofluids J. Appl. Phys. 113, 084307 (2013); 10.1063/1.4793581

Enhancement of thermal conductivity and volumetric behavior of $\mathrm{Fe} \times \mathrm{O}$ y nanofluids

J. Appl. Phys. 110, 014309 (2011); 10.1063/1.3603012

Thermal conductivity of polyethylene glycol nanofluids containing carbon coated metal nanoparticles

J. Appl. Phys. 108, 124304 (2010); 10.1063/1.3486488

Magnetic field induced enhancement in thermal conductivity of magnetite nanofluid

J. Appl. Phys. 107, 09A310 (2010); 10.1063/1.3348387

Thermal conductivity studies of metal dispersed multiwalled carbon nanotubes in water and ethylene glycol based nanofluids

J. Appl. Phys. 106, 084317 (2009); 10.1063/1.3240307

You don't

still use this

cell phone

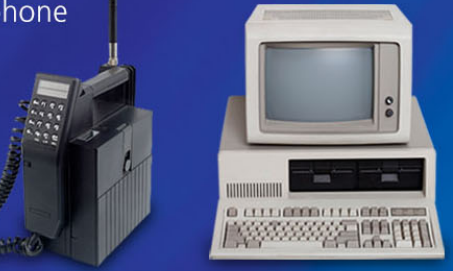

Why are you still using an AFM designed in the 80 's?

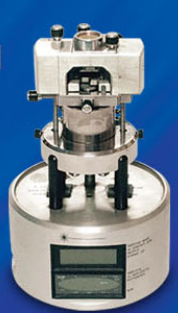

It is time to upgrade your AFM

Minimum $\$ 20,000$ trade-in discount for purchases before August 31st

Asylum Research is today's technology leader in AFM 


\title{
Strong enhancement in thermal conductivity of ethylene glycol-based nanofluids by amorphous and crystalline $\mathrm{Al}_{2} \mathrm{O}_{3}$ nanoparticles
}

\author{
J. Gangwar, ${ }^{1,2}$ A. K. Srivastava, ${ }^{1, a)}$ S. K. Tripathi, ${ }^{2}$ M. Wan, ${ }^{3}$ and R. R. Yadav ${ }^{3}$ \\ ${ }^{1}$ CSIR-National Physical Laboratory, Dr. K. S. Krishnan Road, New Delhi 110012, India \\ ${ }^{2}$ Department of Physics, Panjab University, Chandigarh 160014, India \\ ${ }^{3}$ Department of Physics, University of Allahabad, Allahabad 211002, India
}

(Received 7 June 2014; accepted 3 August 2014; published online 12 August 2014)

\begin{abstract}
In the present work, the temperature and concentration dependence of thermal conductivity (TC) enhancement in ethylene glycol (EG)-based amorphous and crystalline $\mathrm{Al}_{2} \mathrm{O}_{3}$ nanofluids have been investigated at temperatures ranging from 0 to $100^{\circ} \mathrm{C}$. In our prior study, nanometer-sized particles of amorphous-, $\gamma$-, and $\alpha-\mathrm{Al}_{2} \mathrm{O}_{3}$ were prepared via a simple sol-gel process with annealing at different temperatures and characterized by various techniques. Building upon the earlier study, we probe here the crystallinity, microstructure, and morphology of the obtained $\alpha-\mathrm{Al}_{2} \mathrm{O}_{3}$ nanoparticles (NPs) by using X-ray powder diffraction with Rietveld full-profile refinement, scanning electron microscopy, and high-resolution transmission electron microscopy, respectively. In this study, we achieved a $74 \%$ enhancement in TC at higher temperature $\left(100^{\circ} \mathrm{C}\right)$ of base fluid EG by incorporating 1.0 vol. $\%$ of amorphous $-\mathrm{Al}_{2} \mathrm{O}_{3}$, whereas $52 \%$ and $37 \%$ enhancement is accomplished by adding $\gamma$ - and $\alpha-\mathrm{Al}_{2} \mathrm{O}_{3}$ NPs, respectively. The amorphous phase of NPs appears to have good TC enhancement in nanofluids as compared to crystalline $\mathrm{Al}_{2} \mathrm{O}_{3}$. In a nutshell, these results are demonstrating the potential consequences of $\mathrm{Al}_{2} \mathrm{O}_{3}$ NPs for applications of next-generation efficient energy transfer in nanofluids. (C) 2014 AIP Publishing LLC. [http://dx.doi.org/10.1063/1.4893026]
\end{abstract}

To enhance the transport and thermal properties of conventional heat transfer fluids (e.g., water, ethylene glycol (EG), propylene glycol, and engine oil) through nanoparticles additives is an emerging research area in heat transfer science. ${ }^{1-9,19}$ Such increment in the heat transport characteristics of base fluids suggests the crucial benefits which give credence to liquid coolants for moving heat away from electronic, optical, machinery, or nuclear reactor systems. ${ }^{5-7,9}$ Various nanoparticles (NPs) of metals and metal oxides have been added to EG for enhancing the thermal conductivity (TC) of base fluid and are potentially used in heat transfer system. ${ }^{2,5-9,19,21,23-25}$ The nanofluids based on EG reveal a higher TC having nonlinear relationship with temperature. ${ }^{23,29}$ A very recent report to examine the effects of nanoparticle size and temperature has been published focusing on the TC enhancement of water-based $\mathrm{Al}_{2} \mathrm{O}_{3}$ nanfluids. ${ }^{10}$ Owing to the general availability and unique characteristics, such as good structural, chemical and thermal stability at elevated temperatures, high electrical resistivity, low gate leakage, and excellent behavior in optics and electronics, $\mathrm{Al}_{2} \mathrm{O}_{3}$ in both amorphous and polymorphs (material with similar composition but different crystal structure) forms are registered among the technologically most crucial ceramic materials. ${ }^{11-17,27,28}$

In this Letter, we evaluated the effects of ordered/disordered structures of $\mathrm{Al}_{2} \mathrm{O}_{3} \mathrm{NPs}$, volume fraction, and temperatures on the TC enhancement in EG nanofluid for different volume concentrations. As described in a previous work, three different structures of NPs, i.e., amorphous and crystalline $\gamma$, and $\alpha-\mathrm{Al}_{2} \mathrm{O}_{3}$, were synthesized by sol-gel method. We performed here the Rietveld full-profile refinement of $\mathrm{X}$-ray diffraction $(\mathrm{XRD})$ pattern and detailed high-resolution

${ }^{a)}$ Electronic addresses: aks@nplindia.org and avanish.aks555@gmail.com transmission electron microscopy (HRTEM) study of the $\alpha-\mathrm{Al}_{2} \mathrm{O}_{3}$ NPs. All three kinds of amorphous and crystalline structures of $\mathrm{Al}_{2} \mathrm{O}_{3}$ NPs were dispersed in EG-base fluid with different particle loadings to prepare $\mathrm{Al}_{2} \mathrm{O}_{3} / \mathrm{EG}$ nanofluids and determine the enhancement in TC experimentally in a temperature range from 0 to $100^{\circ} \mathrm{C}$.

$\mathrm{Al}_{2} \mathrm{O}_{3} \mathrm{NPs}$ were synthesized via sol-gel method with annealing at three different temperatures. First, a $4 \mathrm{ml}$ saturated aqueous solution of aluminium nitrate nonahydrate $\left(\mathrm{Al}\left(\mathrm{NO}_{3}\right)_{3} \cdot 9 \mathrm{H}_{2} \mathrm{O}\right)$ was prepared at room temperature. Then, the saturated solution was heated at $100^{\circ} \mathrm{C}$ for $30 \mathrm{~min}$ to form the gel and used as the precursor. Finally, the precursor was annealed to obtain $\mathrm{Al}_{2} \mathrm{O}_{3} \mathrm{NPs}$ at 400,800 , and $1000^{\circ} \mathrm{C}$ for $2 \mathrm{~h}$ inside the muffle furnace. As previously reported, the obtained $\mathrm{Al}_{2} \mathrm{O}_{3}$ NPs exhibit amorphous (a-), $\gamma-$, and $\alpha$-crystalline structure of the material. For convenience, the three annealed samples were denoted as a- $\mathrm{Al}_{2} \mathrm{O}_{3}, \gamma-\mathrm{Al}_{2} \mathrm{O}_{3}$, and $\alpha-\mathrm{Al}_{2} \mathrm{O}_{3}$, respectively.

The crystal structure information of the synthesized $\alpha-\mathrm{Al}_{2} \mathrm{O}_{3}$ NPs was determined by XRD (Bruker AXS D8 Advance X-ray diffractometer) using the $\mathrm{Cu}-\mathrm{k} \alpha$ $(\lambda=1.54059 \AA)$ monochromatic radiation, in the $2 \theta$ range between $20^{\circ}$ and $79.8^{\circ}$. Structural refinement for refining the crystalline structure of the $\alpha$-phase in the sample was carried out by the Rietveld method using the program FULLPROF. The morphological identification and size were examined using scanning electron microscope (SEM, Zeiss EVO MA-10) with an acceleration voltage of $10 \mathrm{kV}$. The high-resolution micrographs in real and reciprocal space were acquired with a HR-TEM (FEI Tecnai G2 F30 STWIN) operated at $300 \mathrm{kV}$ accelerating voltage. $\mathrm{Al}_{2} \mathrm{O}_{3}$ nanofluids were prepared by dispersing the synthesized $\mathrm{Al}_{2} \mathrm{O}_{3}$ NPs in EG at three volume percentage of $0.25 \%$, $0.50 \%$, and $1.0 \%$. A hot disc thermal constant analyser 
(model TPS-500) was employed in this study to measure the $\mathrm{TC}$ of the corresponding nanofluids within the temperature range of $0-100{ }^{\circ} \mathrm{C}$.

We present the crystallographic structural characteristics and electron microscopy of the synthesized $\alpha-\mathrm{Al}_{2} \mathrm{O}_{3}$ NPs in Figures 1(a)-1(f). The XRD patterns and morphological details of all three phases (a-, $\gamma-$, and $\alpha-\mathrm{Al}_{2} \mathrm{O}_{3}$ ) have been discussed in our earlier report. ${ }^{11}$ However, the $\alpha$-phase of $\mathrm{Al}_{2} \mathrm{O}_{3}$ which is well crystalline has been dealt again in the present context in regard to its Rietveld refinement. The Rietveldrefined XRD pattern for the $\alpha$-phase structure of $\mathrm{Al}_{2} \mathrm{O}_{3}$ with the observed (red dots), calculated (black solid line), and difference (observed-calculated, blue solid line) spectra is shown in Figure 1(a), resulted in a goodness-of-fit $\left(\chi^{2}\right)$ value of 1.19. The XRD pattern exhibited the $\alpha-\mathrm{Al}_{2} \mathrm{O}_{3}$ NPs crystallized in a rhombohedral structure (space group $R \overline{3} c$, standard JCPDS No. 46-1212) with lattice parameters $a=b=4.758 \AA$ and $c=12.99 \AA$ A . Rietveld-refinement of XRD patterns was performed using the reported parameters of system $\alpha-\mathrm{Al}_{2} \mathrm{O}_{3} .{ }^{11,13}$ The lattice parameters and atomic positions generated by further refinement are listed in Table I. Moreover, all diffraction peaks observed in XRD pattern were sharp and intense suggesting good crystallinity and high purity of the synthesized $\alpha-\mathrm{Al}_{2} \mathrm{O}_{3}$ NPs. Figures 1(b) and 1(c) represent an enlarged view of the prominent peak intensity identified in XRD pattern for (104) and (113) atomic planes, respectively. The corresponding insets elucidate the fine structure arrangement at atomiclevel with lattice spacing of $0.253 \mathrm{~nm}$ and $0.208 \mathrm{~nm}$, indicating that NPs of $\alpha-\mathrm{Al}_{2} \mathrm{O}_{3}$ are defect free. The ball-and-stick representative unit cell of $\alpha-\mathrm{Al}_{2} \mathrm{O}_{3}$ depicted in Figure 1(d) has a hexagonal crystal structure illustrating their atomic stacking layers consists of alternating aluminium $(\mathrm{Al})$ and oxygen $(\mathrm{O})$ planes, whose stacking sequence is ..-O-Al-Al-O-Al-Al-O-Al$\mathrm{Al}-.$. in $\langle 0001\rangle$ direction. In this model, $\mathrm{O}$ atoms are drawn

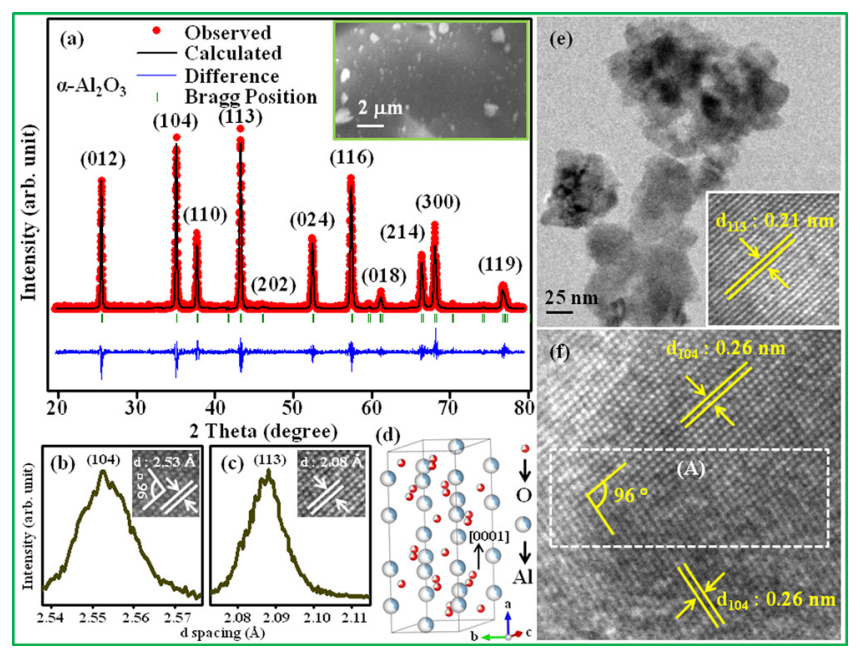

FIG. 1. (a) Rietveld-refined XRD pattern of nano- $\alpha-\mathrm{Al}_{2} \mathrm{O}_{3}$ synthesized by annealing at $1000^{\circ} \mathrm{C}$, (b) and (c) an enlarged view of prominent peak intensity observed in XRD pattern, (d) schematic hexagonal unit cell of $\alpha-\mathrm{Al}_{2} \mathrm{O}_{3}$, color code: $\mathrm{O}$, red (small balls) and $\mathrm{Al}$, light blue (large balls), (e) brightfield TEM image, and (f) high-resolution TEM micrograph; zone A (as delineated by white dotted rectangle) indicates the overlapping of lattice panes. Insets: (a) provides spherical-like morphology obtained using SEM, (b) and (c) show HRTEM images to the corresponding (hkl) planes, and (e) elucidates the fine structure arrangement at atomic-level of $\alpha-\mathrm{Al}_{2} \mathrm{O}_{3}$ nanoparticle.
TABLE I. Rietveld-refined lattice parameters and atomic positions for the $\alpha$-phase structure of $\mathrm{Al}_{2} \mathrm{O}_{3}$.

\begin{tabular}{|c|c|c|c|c|}
\hline \multirow{2}{*}{$\begin{array}{l}\text { Lattice parameters } \\
\text { Space group, } R-3 c\end{array}$} & \multicolumn{4}{|c|}{ Profile parameters } \\
\hline & \multicolumn{2}{|l|}{ Function } & \multicolumn{2}{|c|}{ Pseudo-voigt } \\
\hline \multirow[t]{2}{*}{$\begin{array}{l}\text { (No. 167) } \\
\mathrm{a}=\mathrm{b}=4.76793 \AA \\
\mathrm{c}=13.01579 \AA\end{array}$} & \multicolumn{2}{|l|}{ FWHM parameters } & \multicolumn{2}{|c|}{$\begin{array}{c}\mathrm{U}=-0.04677 \\
\mathrm{~V}=0.11631 \\
\mathrm{~W}=0.00974\end{array}$} \\
\hline & \multicolumn{4}{|c|}{ Atomic positions } \\
\hline Atom label & Wyckoff position & $x$ & $z$ & $O c c$ \\
\hline $\mathrm{O}$ & $18 \mathrm{e}$ & 0.3089 & 0.2500 & 0.674 \\
\hline $\mathrm{Al}$ & $12 \mathrm{c}$ & 0.0000 & 0.3521 & 0.352 \\
\hline Reliability factors & \multicolumn{4}{|c|}{$\mathrm{R}_{\mathrm{p}}: 18.1 \% \mathrm{R}_{\mathrm{wp}}: 28.0 \% \mathrm{R}_{\mathrm{exp}}: 25.62 \% \chi^{2}=1.19$} \\
\hline
\end{tabular}

smaller and $\mathrm{Al}$ atoms are large. ${ }^{12}$ In order to explain the crystal structure of $\alpha-\mathrm{Al}_{2} \mathrm{O}_{3}$, hexagonal unit cell is often more convenient containing 30 atoms $(\mathrm{Al}=12$ atoms, and $\mathrm{O}=18$ atoms). ${ }^{14,17}$ The surface morphology of $\mathrm{Al}_{2} \mathrm{O}_{3}$ NPs is displayed in inset of Figure 1(a), recorded by SEM, illustrating the particles of $\mathrm{Al}_{2} \mathrm{O}_{3}$ have spherical-like structure and size range from 300 to $500( \pm 80) \mathrm{nm}$. Further insight into the morphology, size, and conformation of NPs has been evaluated by HR-TEM analyses. The subsequent TEM studies elucidate that $\mathrm{Al}_{2} \mathrm{O}_{3}$ NPs are in dimension of $15-45 \mathrm{~nm}$, as shown in Figure 1(e). Inset in Figure 1(e) provides the high-resolution TEM micrograph which demonstrates clear regular interlattice plane distance of $0.21 \mathrm{~nm}$, consistent with the (113) plane of $\alpha-\mathrm{Al}_{2} \mathrm{O}_{3}$ crystal, indicating that the NPs of $\alpha-\mathrm{Al}_{2} \mathrm{O}_{3}$ are perfect and in good crystalline nature. The lattice-resolved HRTEM image elucidates in Figure 1(f) revealing an interlattice plane distance of $0.26 \mathrm{~nm}$, corresponds to (104) plane of $\alpha-\mathrm{Al}_{2} \mathrm{O}_{3}$, which is almost perpendicular $\left(\sim 96^{\circ}\right)$ to each other (denoted by white dotted rectangle area; zone A), further authenticates the high-crystalline nature of $\alpha-\mathrm{Al}_{2} \mathrm{O}_{3}$ NPs.

We compared the TC of EG-based a-, $\gamma$-, and $\alpha-\mathrm{Al}_{2} \mathrm{O}_{3}$ nanofluids over a broad range of temperature (from 0 to $100^{\circ} \mathrm{C}$ ) for the particle addition of $0.25,0.50$, and $1.0 \mathrm{vol} . \%$. Three volume concentrations were employed to study the effect of NPs concentration on the TC of base fluid. Figures 2(a), 2(b), and 2(c) represent the temperaturedependent \% TC enhancement as a function of NPs additive loading of a- $\mathrm{Al}_{2} \mathrm{O}_{3} / \mathrm{EG}, \gamma-\mathrm{Al}_{2} \mathrm{O}_{3} / \mathrm{EG}$, and $\alpha-\mathrm{Al}_{2} \mathrm{O}_{3} / \mathrm{EG}$ nanofluids, respectively. The \% TC enhancement can be expressed as follows:

$$
\% \text { TC enhancement }=\left[\left\{K_{n f}-K_{b f}\right\} / K_{b f}\right] \times 100,
$$

where $\mathrm{K}_{\mathrm{nf}}$ and $\mathrm{K}_{\mathrm{bf}}$ represents the thermal conductivity of nanofluid and base-fluid, respectively.

Moreover, to predict and explain the TC enhancement in nanofluids, numerous theoretical studies have been focused and debated extensively over the past decade., ${ }^{3,10,18-23}$ Several participating factors include Brownian motion of NPs, internanoparticle potential, radiative heat transfer, particle aggregation, and dynamic interactions have been attempted to account the anomalous enhancement in TC of nanofluids combined with the effects of NPs size and shape, volume concentration of NPs, and temperature. ${ }^{2,6,10,19,21-26}$ 


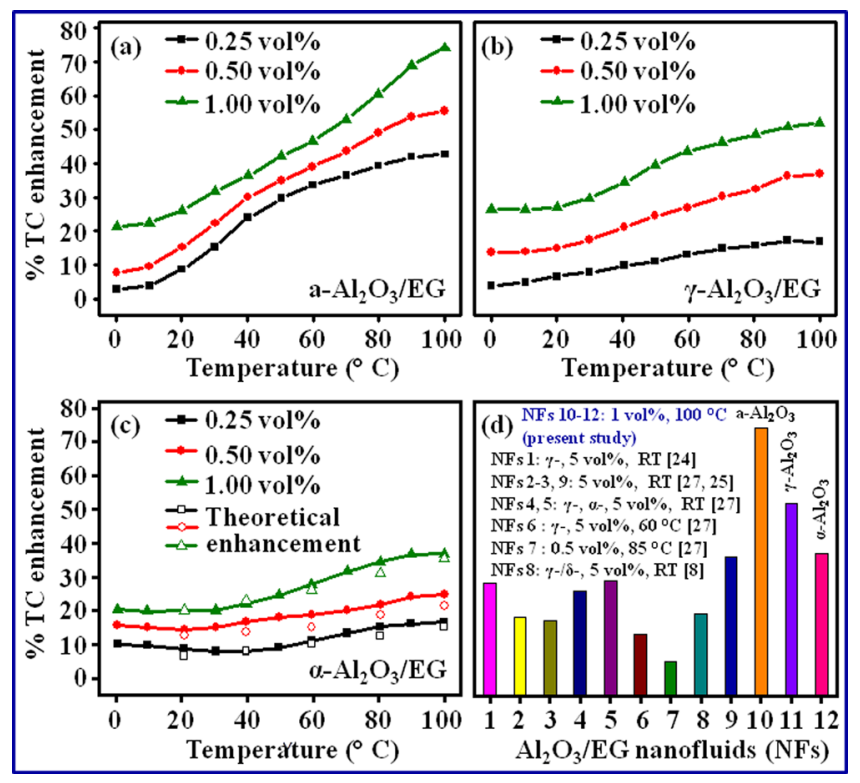

FIG. 2. Temperature dependence of \% TC enhancement (TCE) of (a) amorphous- $\mathrm{Al}_{2} \mathrm{O}_{3} / E G$, (b) $\gamma-\mathrm{Al}_{2} \mathrm{O}_{3} / E G$, and (c) $\alpha-\mathrm{Al}_{2} \mathrm{O}_{3} / E G$ nanofluids at NPs additive loadings of $0.25,0.50$, and 1.0 vol. \%. Color code: black, red, and green (square, circle, and up-triangle in shape) solid (in (a), (b), (c)) and open (in (c)) contours represent experimental and theoretical \% TC enhancement, respectively. (d) Histogram illustrating a comparative study of some of the best TCE recorded for different polymorphs $\mathrm{Al}_{2} \mathrm{O}_{3} / \mathrm{EG}$ nanofluids in previous literature and in the present study; RT indicates the room temperature.

In addition to describe the enhancement in TC of EG fluid with volume fraction/particle loadings of NPs, the model of Prasher et al. for the TC enhancement ratio of nanofluid is given as follows: ${ }^{5,6,21}$

$$
\frac{K_{n f}}{K_{b f}}=\left(1+A R_{e}^{m} P_{r}^{0.333} \phi\right)\left[\frac{(1+2 \alpha)+2 \phi(1-\alpha)}{(1+2 \alpha)-\phi(1-\alpha)}\right],
$$

where $\phi$ is the particle volume fraction, $\alpha=2 R_{b} K_{b f} / d_{N P}$, and $R_{b}$ is the interfacial resistance. $P_{r}$ is Prandtl number and $d_{N P}$ is diameter of nanoparticle. The Reynolds number $\mathrm{R}_{\mathrm{e}}$ can be written as

$$
R_{e}=\frac{1}{v} \sqrt{\frac{18 k_{B} T}{\pi \rho_{N} d_{N P}}}
$$

where $\nu$ is the kinematic viscosity, $\rho_{N}$ is density of the liquid, $k_{B}$ is Boltzmann constant, and $\mathrm{T}$ is temperature in Kelvin scale.

Figure 2(c) provides the order of magnitude calculations for \% TC enhancement based on the above model in $\alpha-\mathrm{Al}_{2} \mathrm{O}_{3} / \mathrm{EG}$ nanofluid at different particle loadings and temperatures along with the experimental observations. This model includes the effect of particle diameter on TC enhancement of nanofluid. Numerical values of all required parameters are obtained as suggested by the above mentioned model. Here, we have taken $R_{b}=9 \times 10^{-8} \mathrm{~K} \mathrm{~m}^{2} \mathrm{~W}^{-1}$, average particle diameter $d_{N P}=70 \mathrm{~nm}, P_{r}=10$, and density of $\mathrm{Al}_{2} \mathrm{O}_{3}=3.95 \mathrm{~g} / \mathrm{cm}^{3} . \mathrm{A}=40000$ and $\mathrm{m}=2.9$ are bets fit parameters. The calculated \% TC values for vol. \%- and temperature-dependent seemed to be in good agreement with our experimental investigations. We have measured the TC
TABLE II. Temperature-dependent $\%$ thermal conductivity enhancement (TCE) of a-, $\gamma$-, and $\alpha-\mathrm{Al}_{2} \mathrm{O}_{3} / \mathrm{EG}$ nanofluids for different volume concentrations.

\begin{tabular}{lcccc}
\hline \hline & & \multicolumn{3}{c}{$\%$ TCE at different temperatures } \\
\cline { 3 - 5 } Nanofluids & vol. \% & $30{ }^{\circ} \mathrm{C}$ & $80^{\circ} \mathrm{C}$ & $100{ }^{\circ} \mathrm{C}$ \\
\hline $\mathrm{a}-\mathrm{Al}_{2} \mathrm{O}_{3} / \mathrm{EG}$ & 0.25 & 15.28 & 39.32 & 42.70 \\
& 0.50 & 22.27 & 49.14 & 55.54 \\
& 1.00 & 31.69 & 60.42 & 74.15 \\
$\gamma-\mathrm{Al}_{2} \mathrm{O}_{3} / \mathrm{EG}$ & 0.25 & 7.70 & 15.67 & 16.77 \\
& 0.50 & 17.33 & 32.44 & 36.90 \\
& 1.00 & 29.58 & 48.66 & 52.03 \\
$\alpha-\mathrm{Al}_{2} \mathrm{O}_{3} / \mathrm{EG}$ & 0.25 & 7.99 & 15.23 & 16.58 \\
& 0.50 & 15.14 & 21.67 & 24.73 \\
& 1.00 & 20.13 & 34.48 & 36.93 \\
\hline \hline
\end{tabular}

of pure a-, $\gamma$-, and $\alpha-\mathrm{Al}_{2} \mathrm{O}_{3}$ powder at room temperature and it is $0.495,0.459$, and $0.377 \mathrm{~W} / \mathrm{mK}$, respectively. This difference in TC may be an important reason for difference in TC enhancement in different polymorphs of $\mathrm{Al}_{2} \mathrm{O}_{3}$.

As expected, the enhancement in TC of $\mathrm{Al}_{2} \mathrm{O}_{3} / \mathrm{EG}$ nanofluids is achieved with increasing volume concentrations of NPs and temperatures. We achieve the higher enhancement in TC of EG-based $\mathrm{Al}_{2} \mathrm{O}_{3}$ nanofluids as displayed in Figure 2(d), histogram demonstrating a comparative study of some of the best TC enhancements recorded for different parameters of $\mathrm{Al}_{2} \mathrm{O}_{3} / \mathrm{EG}$ nanofluids. The temperature dependence \% TC enhancement at different volume concentrations of a-, $\gamma$-, and $\alpha-\mathrm{Al}_{2} \mathrm{O}_{3} / \mathrm{EG}$ nanofluids is presented in Table II. The TC enhancement for similar NPs loadings with increasing temperature is more pronounced for a- $\mathrm{Al}_{2} \mathrm{O}_{3} / \mathrm{EG}$ nanofluids than for $\gamma$ - and $\alpha-\mathrm{Al}_{2} \mathrm{O}_{3} / \mathrm{EG}$ nanofluids by more than a factor of 1.5 and 2, respectively, which is higher than any of the results reported previously for $\mathrm{Al}_{2} \mathrm{O}_{3} / \mathrm{EG}$ nanofluids (Figure 2(d)). The different trends in TC enhancements are probably due to the differences in size of particles, as the particle size decreases, the surface-to-volume ratio of particles increases, can lead to enhance the TC of nanofluids. In our earlier study, the formation of bigger grain like particles is observed with increasing the annealing temperature. ${ }^{11}$ Although the reason for the observed monotonic trend in the enhancement of TC of nanofluid system can be accounted by the dependence of different crystal structure of NPs or the influence of interfacing between liquid-phase and solidmaterial, collisions between the base fluid molecule and interfacial thermal resistance may be considered. ${ }^{2,6,26}$ Since nano-amorphous particle is more open structure than nanocrystalline material, in which individually atoms are randomly distributed may form long-range thermal transfer channels, it is clear that particles with different crystallinity influence heat transfer differently, as schematically depicted in Figure 3. The long-range order in nano-crystalline may resist to the liquid-particle interface and resulted in the lower enhanced TC of the crystalline $\gamma$ - and $\alpha-\mathrm{Al}_{2} \mathrm{O}_{3} / \mathrm{EG}$ nanofluids. Moreover, the amorphous structure of $\mathrm{Al}_{2} \mathrm{O}_{3}$ has random distribution of $\mathrm{Al}^{3+}$ and vacancies over tetrahedral $\left(\mathrm{AlO}_{4}\right)$, polyhedral $\left(\mathrm{AlO}_{5}\right)$, and octahedral $\left(\mathrm{AlO}_{6}\right)$ sites with the prominent tetrahedral and octahedral units; whereas the crystal structure of $\gamma-\mathrm{Al}_{2} \mathrm{O}_{3}$ is composed of a mixture of tetrahedral and 


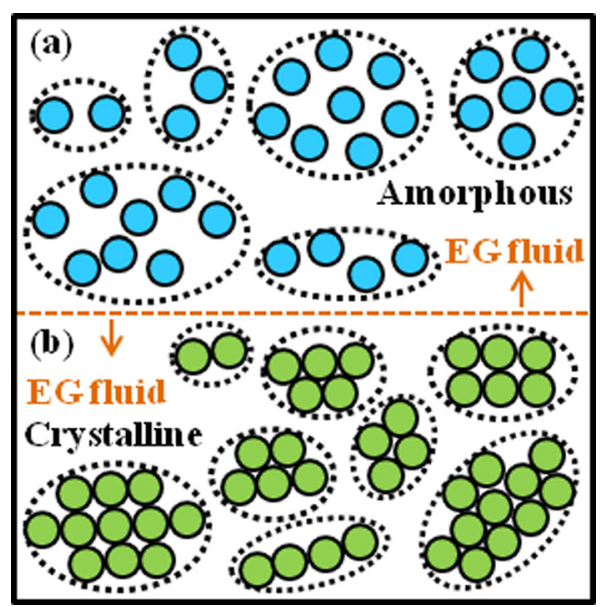

FIG. 3. Schematic representation of the interfacing for the (a) amorphous and (b) crystalline structures of NPs in a base fluid; the blue balls in upper segment indicate the amorphous structure and the green balls in lower segment indicate the crystalline structure of NPs.

octahedral with corner sharing oxygen atoms, and $\alpha-\mathrm{Al}_{2} \mathrm{O}_{3}$ involved only $\mathrm{Al}^{3+}$ in octahedral units. ${ }^{12,15,27,28}$ We infer that the predominant fractions of a- $\mathrm{Al}_{2} \mathrm{O}_{3} \mathrm{NPs}$ may highly interact with the base-fluid and enhance the TC of nanofluids. The lower TC enhancement achieved by the crystalline $\gamma$ - and $\alpha-\mathrm{Al}_{2} \mathrm{O}_{3} / \mathrm{EG}$ nanofluids can be ascribed due to the presence of short-range interfacing between solid-particle and liquidphase as compared to the a- $\mathrm{Al}_{2} \mathrm{O}_{3} /$ EG nanofluids. ${ }^{25,30}$ Based on the results, we conclude that the NPs size, interfacing with liquid, volume fraction of NPs in nanofluids, and temperature affect the $\mathrm{TC}$ of $\mathrm{Al}_{2} \mathrm{O}_{3} / \mathrm{EG}$ nanofluids.

In conclusion, we performed the crystallinity determination and morphological identification using Reitveldrefinement XRD analysis and electron microscopy of $\alpha-\mathrm{Al}_{2} \mathrm{O}_{3}$ NPs. We evaluated the TC enhancement of ethylene glycol-based $\mathrm{Al}_{2} \mathrm{O}_{3}$ nanofluids, the results corroborate that such nanofluids reveal higher TC than their base fluid and increases with NPs addition and temperatures. We observe, however, that the particle-liquid interfacing is the main reason for the obtained improvement in TC of nanofluids. Such enhancement reveals that $\mathrm{Al}_{2} \mathrm{O}_{3}$ nanoparticles can be considered as ubiquitous in the advancement for the energyefficient heat transfer applications.

The financial assistance from UGC, New Delhi, through Grant No. F.2-61/98 (SA-I) is gratefully acknowledged. The authors sincerely thank the Director, NPL New Delhi, India for providing the necessary experimental facilities. Dr. N. Vijayen, Mr. K. N. Sood and Mr. J. S. Tawale are gratefully acknowledged for extending their kind support during XRD and SEM measurements, respectively.

${ }^{1}$ D. T. Wasan and A. D. Nikolov, Nature 423, 156 (2003).

${ }^{2}$ B. T. Branson, P. S. Beauchamp, J. C. Beam, C. M. Lukehart, and J. L. Davidson, ACS Nano 7, 3183 (2013).

${ }^{3}$ Z. Liang and H. L. Tsai, Phys. Rev. E 83, 041602 (2011).

${ }^{4}$ J. W. Gao, R. T. Zheng, H. Ohtani, D. S. Zhu, and G. Chen, Nano Lett. 9, 4128 (2009).

${ }^{5}$ J. Gangwar, K. K. Dey, S. K. Tripathi, M. Wan, R. R. Yadav, R. K. Singh, Samta, and A. K. Srivastava, Nanotechnology 24, 415705 (2013).

${ }^{6}$ P. D. Shima, J. Philip, and B. Raj, J. Phys. Chem. C 114, 18825 (2010).

${ }^{7}$ J. J. T. Tijerina, T. N. Narayanan, C. S. Tiwary, K. Lozano, M. Chipara, and P. M. Ajayan, ACS Appl. Mater. Interfaces 6, 4778 (2014).

${ }^{8}$ M. J. P. Gallego, L. Lugo, J. L. Legido, and M. M. Piñeiro, Nanoscale Res. Lett. 6, 221 (2011).

${ }^{9}$ C. Zhi, Y. Xu, Y. Bando, and D. Golberg, ACS Nano 5, 6571 (2011).

${ }^{10}$ J. H. Lee, S. H. Lee, and S. P. Jang, Appl. Phys. Lett. 104, 161908 (2014).

${ }^{11}$ J. Gangwar, K. K. Dey, Komal, Praveen, S. K. Tripathi, and A. K. Srivastava, Adv. Mater. Lett. 2, 402 (2011).

${ }^{12}$ N. Shibata, M. F. Chisholm, A. Nakamura, S. J. Pennycook, T. Yamamoto, and Y. Ikuhara, Science 316, 82 (2007).

${ }^{13}$ J. F. Lin, O. Degtyareva, C. Prewitt, P. Dera, N. Sata, E. Gregoryanz, H. K. Mao, and R. J. Hemley, Nat. Mater. 3, 389 (2004).

${ }^{14}$ Y. Lei, Y. Gong, Z. Duan, and G. Wang, Phys. Rev. B 87, 214105 (2013).

${ }^{15}$ A. H. Tavakoli, P. S. Maram, S. J. Widgeon, J. Rufner, K. V. Benthem, S. Ushakov, S. Sen, and A. Navrotsky, J. Phys. Chem. C 117, 17123 (2013).

${ }^{16}$ R. M. Laine, J. C. Marchal, H. P. Sun, and X. Q. Pan, Nat. Mater. 5, 710 (2006).

${ }^{17}$ E. Wallin, J. M. Andersson, E. P. Münger, V. Chirita, and U. Helmersson, Phys. Rev. B 74, 125409 (2006).

${ }^{18}$ V. Sridhara and L. N. Satapathy, Nanoscale Res. Lett. 6, 456 (2011).

${ }^{19}$ K. K. Dey, A. Kumar, R. Shanker, A. Dhawan, M. Wan, R. R. Yadav, and A. K. Srivastava, RSC Adv. 2, 1387 (2012).

${ }^{20}$ R. Zheng, J. Gao, J. Wang, S. P. Feng, H. Ohtani, J. Wang, and G. Chen, Nano Lett. 12, 188 (2012).

${ }^{21}$ R. Prasher, P. Bhattacharya, and P. E. Phelan, Phys. Rev. Lett. 94, 025901 (2005).

${ }^{22}$ M. P. Beck, T. Sun, and A. S. Teja, Fluid Phase Equilib. 260, 275 (2007).

${ }^{23}$ K. K. Dey, P. Kumar, R. R. Yadav, A. Dhar, and A. K. Srivastava, RSC Adv. 4, 10123 (2014).

${ }^{24}$ H. Xie, W. Yu, and W. Chen, J. Exp. Nanosci. 5, 463 (2010).

${ }^{25}$ M. Yasaswi, R. V. Prasad, and T. J. Kumar, Int. J. Mech. Ind. Eng. 2, 112 (2012).

${ }^{26}$ D. Lee, Langmuir 23, 6011 (2007).

${ }^{27}$ C. Pan, S. Y. Chen, and P. Shen, J. Phys. Chem. B 110, 24340 (2006).

${ }^{28}$ V. V. Hoang, Phys. Rev. B 70, 134204 (2004).

${ }^{29}$ E. V. Timofeeva, A. N. Gavrilov, J. M. McCloskey, Y. V. Tolmachev, S. Sprunt, L. M. Lopatina, and J. V. Selinger, Phys. Rev. E 76, 061203 (2007).

${ }^{30}$ J. T. Tijerina, T. N. Narayanan, G. Gao, M. Rohde, D. A. Tsentalovich, M. Pasquali, and P. M. Ajayan, ACS Nano 6, 1214 (2012). 